\title{
An unusual blood pressure reading
}

\author{
Étienne de Médicis, MD, MSc, FRCPC (1)
}

Received: 4 September 2017/Revised: 22 September 2017/Accepted: 10 October 2017/Published online: 16 October 2017

(C) Canadian Anesthesiologists' Society 2017

The non-invasive blood pressure (NIBP) reading shown in the image (bottom right part of the screen) was obtained during abdominal oncological surgery. The NIBP monitor was placed on the right arm with the invasive arterial cannula in the left radial artery. On the upper left side of the monitor's screen, there is a 30-min trend. The third reading from the top shows stable arterial blood pressure at the time of the NIBP reading, within the same systolic blood pressure range. This was the only anomalous NIBP reading during the case. After the operation, the NIBP equipment was checked and found to be in normal operating condition.

Automatic NIBP monitors use oscillometry to obtain their readings. The pressure at the maximum oscillometric amplitude corresponds to the mean blood pressure. As the NIBP cuff deflates, systolic and diastolic blood pressures are obtained for pressure at specific oscillometric amplitudes above and below the maximum oscillometric amplitude calculated according to algorithms belonging to each manufacturer. ${ }^{1,2}$ In this case, we hypothesized that, as the NIBP cuff deflated after the maximum oscillometric amplitude was reached (i.e., mean blood pressure was obtained and the systolic blood pressure calculated according to the algorithm), the surgeon applied physical pressure on the NIBP cuff at the exact time that the calculated oscillometric amplitude for the diastolic blood pressure was attained, increasing the pressure within the NIBP cuff above the systolic NIBP reading. That action

É. de Médicis, MD, MSc, FRCPC ( $₫)$

Département d'anesthésiologie, Université de Sherbrooke,

Sherbrooke, QC, Canada

e-mail: estria1@globetrotter.net

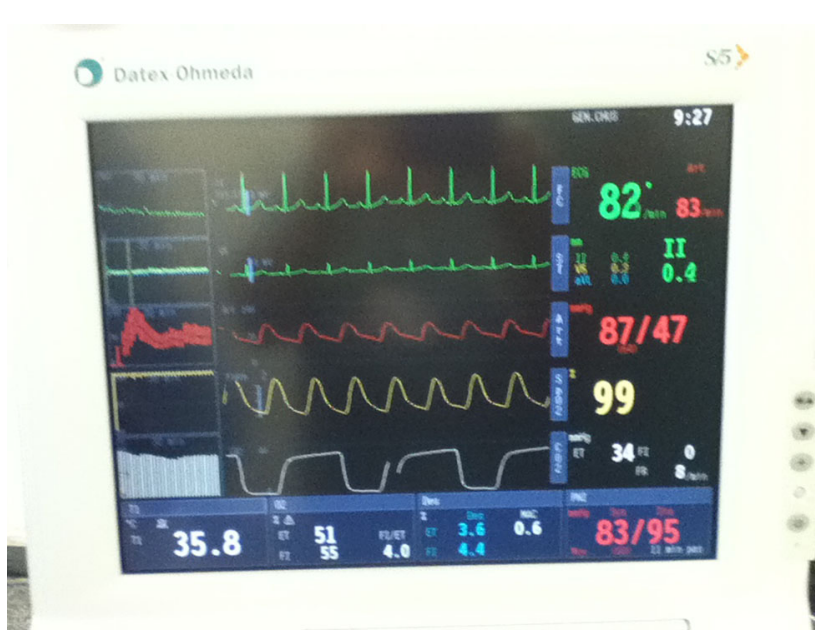

Figure A photograph from the patient monitoring screen showing an erroneous non-invasive blood pressure reading with the diastolic blood pressure being higher than the systolic blood pressure

would explain the erroneous reading of a diastolic blood pressure being higher than the systolic blood pressure.

Conflicts of interest None declared.

Editorial responsibility This submission was handled by Dr. Philip M. Jones, Associate Editor, Canadian Journal of Anesthesia.

\section{References}

1. Dorsch JA, Dorsch SA. Understanding Anesthesia Equipment, 5th Edition. Wolters Kluwer Health, Lippincott Williams \& Wilkins 2008; 27: 837-44.

2. Bartels K, Esper SA, Thiele RH. Blood pressure monitoring for the anesthesiologist: a practical review. Anesth Analg 2016; 122: 1866-79. 